\title{
Benefícios do mapeamento do genoma humano em oncologia
}

\author{
Vagner da Silva Tiburtino*, Tatiana Milovanovitch**
}

${ }^{*}$ Graduando Enfermagem da Universidade Nove de Julho, ${ }^{* *}$ Docente MBA e Especialista em Administração Hospitalar e Serviço de Saúde do Curso de Enfermagem da Universidade Nove de Julho - Artigo apresentado à Universidade Nove de Julho referente ao Trabalho de Conclusão de Curso para obtenção do titulo de Enfermeiro

\section{Resumo}

O genoma significa toda informação hereditária de um ser vivo codificada no DNA, e seu mapeamento traz avanços para o entendimento de diversos tipos de câncer, desenvolvimento de diagnósticos, prognósticos e fármacos específicos. Este trabalho tem como objetivo descrever os benefícios do mapeamento do genoma humano na prevenção e tratamento do câncer em pacientes adultos. Trata-se de uma revisão bibliográfica realizada em bancos de dados online. O estudo revelou que por meio das pesquisas genômicas surgiu a categoria de risco genético, sendo uma nova explicação no processo saúde e doença. Através de estudos genômicos, consegue-se determinar todas as funções de todos os genes, e saber das suas interaçóes com fatores ambientais, em busca de conhecer a etiologia do câncer, bem como melhor diagnóstico, prognóstico e tratamento.

Palavras-chave: genoma humano, proteômica, genômica, neoplasias.

\section{Abstract \\ Benefits of mapping human genome in oncology}

The genome means the entirety of an organism's hereditary information encoded in DNA, and its mapping presents significant advance to understand different types of cancer, to develop diagnostics, prognostics and specific drugs. The aim of this study was to describe the benefits of mapping the human genome for the prevention and treatment of cancer in adult patients. It was a literature review using online databases. The study revealed that through genomic researches emerged the category of genetic risk, being a new explanation for the health-disease process. We may determine using the genomic studies all functions of all genes, and learn about their interactions with environmental factors, searching for the etiology of cancer, as well as better diagnosis, prognosis and treatment.

Key-words: human genome, proteomics, genomics, neoplasms. 


\section{Resumen}

\section{Beneficios de la cartografía del genoma humano en oncología}

Genoma es el conjunto de información hereditaria de un ser vivo codificada en el ADN, y la cartografía aporta avances en la comprensión de los diversos tipos de cáncer, en el desarrollo de diagnósticos, pronósticos y medicamentos específicos. Este estudio tiene como objetivo describir los beneficios de la cartografía del genoma humano en la prevención y tratamiento del cáncer en pacientes adultos. Se trata de una revisión de la literatura usando buscadores de bases de datos online. El estudio reveló que por medio de la investigación genómica surgió la categoría de riesgo genético, con una nueva explicación del proceso salud y enfermedad. A través de estudios genéticos, es posible determinar todas las funciones de todos los genes, y saber de sus interacciones con factores ambientales, buscando conocer la etiología del cáncer, así como un mejor diagnóstico, pronóstico y tratamiento.

Palabras-clave: genoma humano, proteómica, genómica, neoplasias.

\section{Introdução}

Após completar o Projeto Genoma Humano com o mapeamento de todos os genes, entramos na era genômica e um novo caminho para a ciência desvendar os segredos do genoma humano, gerando avanços e mudanças, com informaçóes obtidas por mais de 15 anos de projeto, finalmente convertidos em benefícios, despertando interesse mundial na área científica, servindo de aplicaçóes genéticas para esclarecimento de doenças como câncer $[1,2]$.

Aproximadamente 25 mil genes compóem o genoma humano. $\mathrm{O}$ grande objetivo da ciência é desvendar as funçóes dos genes e o que condiciona suas alteraçóes. Estamos a vida inteira expostos a fatores externos como alimentação, atividade física, medicamentos, poluição, estresse, exposição ao sol etc, por isso o estudo do genoma é importante para saber qual é o impacto para a saúde humana [3].

A era genômica tem como conceito ser a ciência que estuda os genes e suas funções, servindo para o entendimento do câncer, pois nos detalhará o funcionamento normal dos genes, levando a desenvolver formas de controle do seu correto funcionamento. Além disso, doenças que limitam o tempo de vida e causam sequelas poderâo ser normalizadas/curadas ainda intra-útero, doenças genéticas, cânceres etc. nos fornecendo mecanismos para a prevenção de maneira precisa, desenvolvimento de medicamentos específicos e individuais conhecidos como tratamentos customizados [4].

O genoma é definido como conjunto de material genético que sofre alteraçóes gradualmente, para seus descendentes; já o transcritoma, o proteoma e o metaboloma são quantitativos em um determinado momento de transcritos, proteínas e metabólitos, ocorrendo modificaçóes constantes, devido a diversas causas ambientais [5].

Com o término do sequenciamento do genoma humano, esclareceu-se que existem profundas diferenças entre pessoas quanto a seus fenótipos, mas seus genomas apresentam semelhança de 99,9\%, havendo variação de indivíduo para indivíduo de $0,1 \%$. Essas variaçóes ocorrem, principalmente, por alteraçốes discretas na sequência do DNA, nomeadas de polimorfismos de nucleotídeo único ( $S N P$ ), ocorrendo em milhóes no genoma humano. Os SNPS podem levar a alteraçóes na função, localização, estrutura e quantidade de proteínas codificadas, modificando diversas fases fisiológicas. Também há possibilidade de alterar características físicas, portanto podem desencadear o desenvolvimento de doenças crônicas não-transmissíveis (DCNT) como os cânceres [3].

As células cancerosas evoluem, sofrem modificaçôes cromossômicas estruturais como deleções, translocações e inversões. Essas alterações cromossômicas podem levar a expressão anormal de muitos genes, desenvolvendo o estágio oncológico [6].

O termo genômica, criado há quase duas décadas, é definido como a classe que estuda o genoma. A palavra genoma surgiu da fusão entre gene e cromossomo, nomeando esta parte da ciência genética que surgiu em 1920. Ampliou-se consideravelmente ramificando-se em subdisciplinas, utilizando o sufixo "ômico", tendo como matriz a genômica, que estuda todo o material genético contido na célula, direcionando os estudos aos produtos, expressóes e interaçôes gênicas que são: proteômica (conjunto de proteínas expressas), transcriptômica, metabonômica, para relacionar os metabólitos presentes em determinadas situaçóes, nutrigenômica, alimentos 
e farmacogenômica, que se refere aos fármacos para terapia gênica [7].

O mapeamento clarificou a sequência dos genes, já que este acontecimento isoladamente não é o suficiente para definir a funçáo de cada gene, por isso da importância das subclasses com o sufixo ômico. Conhecer as funçóes de todos os genes e caracterizar suas interaçôes com fatores externos é tarefa possível, devido ao mapeamento do genoma humano $[5,8]$.

Com o avanço da ciência, os estudos em oncologia evoluíram bruscamente, nos últimos 20 anos, quando se observou que é uma patologia proveniente de alteraçóes no genoma. A oncogenômica visa respostas para questôes relacionadas ao processo de tumorigênese em humanos, devido aos múltiplos estágios que refletem as alteraçôes genéticas, desencadeando processos de transformaçóes de uma célula normal em uma célula maligna. Então, como deixar os tumores inativos de forma permanente, quais pacientes necessitarão ou não de terapias sistêmicas e quais drogas deverão ser utilizadas nas várias linhas de pesquisa são questóes que a oncogenômica visa respondê-las para os diversos tipos de oncogênese [9].

O tema foi escolhido devido às pesquisas em câncer terem avançado rapidamente nas últimas décadas, mostrando ser uma doença que envolve alteraçóes dinâmicas no genoma. Este trabalho tem como objetivo descrever os benefícios do mapeamento do genoma humano na prevençáo, diagnóstico e tratamento do câncer em pacientes adultos.

\section{Material e métodos}

Trata-se de uma revisão bibliográfica, através de pesquisa metodológica, a partir dos seguintes descritores: Genoma humano, Proteômica, Instituto Nacional de Pesquisa em Genoma Humano (U.S.), Genômica, Neoplasias. A busca dos artigos foi realizada nos seguintes bancos de dados: Medline (13 artigos), Equidad (4), Lilacs (39), Adolec (10), BBO (3), IBECS (33), NHS-EED (1), HTA (2), tendo um total de 105 artigos. Após o levantamento destes artigos deu-se início a uma leitura analítica, selecionando 20 artigos pertinentes referentes ao tema proposto, sendo 04 de língua inglesa e 16 na língua portuguesa, iniciando a redação deste projeto de pesquisa. Os critérios de inclusão foram: utilizar publicaçóes a partir do ano de $2005 \mathrm{em}$ língua inglesa e portuguesa; os critérios de exclusão foram: publicações que não focavam os benefícios do mapeamento do genoma humano na prevenção, diagnóstico e tratamento do câncer e fora do período de publicação estabelecido e demais idiomas. A coleta de dados teve duração de 4 meses [10].

\section{Resultados e discussão}

A era pós-genoma permitiu avanço no diagnóstico/prognóstico e na terapêutica do câncer, devido a determinar fenômenos moleculares, que acompanham a carcinogênese e os eventos que caracterizam o comportamento de diferenciação/malignidade de uma neoplasia e suas lesóes, sendo marcadores dos processos de oncogênese. A oncologia usa critérios morfológicos para determinar a agressividade de um tumor, como: número de mitoses, tipo histológico, grau do pleomorfismo celular, resposta inflamatória, acometimento de vasos sanguíneos e linfáticos. Os aspectos relacionados à biologia dos tumores, além das características clínicas e histopatológicas, visam prever a evolução das lesóes, independentes do procedimento adjuvante e sua resposta a um determinado tipo de terapia, definindo os fatores prognósticos e preditivos [11].

A seguir abordaremos os principais acontecimentos na era pós-mapeamento do genoma humano relacionados à oncologia que são: Microarrays, MicroRNAs, Marcadores séricos e espectrometria de massa, Papiloma vírus, Carcinoma de mama, Marcadores biológicos no câncer de boca, Nutrição no pós-genoma, Proteínas quinases e Enfermagem na era genômica, estes avanços contribuem para as realizaçóes de intervençóes precisas na oncologia [11-13].

\section{Microarrays}

Para determinar os padróes da expressão gênica em amostras biológicas, são utilizados os microarrays ou chips de $D N A$ que são eficazes, pois realizam a caracterização da expressão em milhares de genes ao mesmo tempo. Isso permite que os cientistas comparem o comportamento molecular e detectem os variados tipos celulares de diferentes tecidos, quando suscetíveis a uma condição patológica ou experimental, gerando novos caminhos para análise das fases fisiológicas, condicionando a identificação de marcadores moleculares, que servem como meio diagnóstico, prognóstico e para determinar o resultado do tratamento farmacológico atual, devido a 
detectar o aumento substancial, com a capacidade analítica dos processos moleculares. É uma ferramenta que fornece informaçóes aos cientistas, para examinarem comparativamente a expressão gênica global, em variados tipos celulares e/ou tecido específico, quando estes estejam acometidos por patologias ou em modo experimental. Tem como grande vantagem ser possível identificar as variações estruturais na sequência do DNA, que possam evoluir para o aumento do acometimento da patologia de uma maneira rápida, econômica e sistemática [2].

\section{MicroRNAs}

Há diversos tumores associados à expressão alterada de microRNAs, podendo agir como oncogenes ou genes que podem ser supressores de tumores. Os microRNAs definem-se como uma nova classe de $R N A s$ endógenos, com função de inibir a tradução dos $R N A$ s e sua expressáo anômala tem sido relacionada a diversos tipos de cânceres. Tem como papel a cura do câncer, pois são reguladores fundamentais da expressão gênica em humanos, em que $50 \%$ dos genes de microRNAs ficam localizados em sítios genômicos associados ao câncer [12].

\section{Marcadores séricos e espectrometria de massa}

As metodologias do mapeamento do genoma humano advêm da engenharia genética, gerando todo o conhecimento sobre o genoma, impulsionando a proteoma, essa metodologia permitiu rastrear a presença e a localização de proteínas nas células, determinando os marcadores de doenças e alvos de medicamentos [14].

Proteômica é a ciência que estuda o conjunto de proteínas expressas num determinado tempo, tendo grande importância, devido às atividades das proteínas estarem proximamente associadas às funções dos genes, já que são os produtos finais da regulação da atividade gênica. É uma importante técnica de melhoramento genético se diferenciando dos marcadores fenotípicos ou baseados em DNA, pois a proteômica gera dados em nível molecular das variedades genéticas, sendo claramente expressa do genoma e complementa os estudos na biologia molecular das células [8].

Os estudos biomoleculares objetivam genes, $R N A s$, proteínas e moléculas ligadas ao metabolismo. Biomarcador é toda molécula ou característica biológica que possa ser detectada e/ou medida, determinando processos biológicos normais, patológicos ou a resposta medicamentosa, após intervenção terapêutica, revelando diferenças do estado fisiológico normal para o de enfermidade, diferenças no ambiente corporal interno ou no meio ambiente. Com o surgimento da eletroforese bidimensional (2D) de alta resolução e as técnicas de espectrometria de massa $(E M)$, é possível ionizar uma biomolécula sem degradá-la. Essas técnicas são vantajosas, pois a partir delas somos capazes de observar/analisar centenas de proteínas ao mesmo tempo [14].

Marcadores séricos são proteínas secretadas por tumores, que podem ser observadas em concentraçôes femtomolares, por medidas de espectometria de massa, servindo para diagnóstico do câncer. A espectrometria de massa aplicada para determinaçáo de fluidos biológicos tem como objetivo identificar biomarcadores para diagnóstico, rastrear em segundos padróes moleculares diferentes entre pessoas normais e com câncer. Os resultados da literatura destacam a espectrometria de massa como método promissor no futuro do diagnóstico de doenças [14].

\section{Papiloma vírus}

O papilomavírus humano (HPV) é vírus de DNA, apontado como agente etiológico do câncer cervical. A infecção ocorre primariamente no epitélio e pode desencadear lesóes benignas ou malignas na pele e na mucosa, existindo tipos de HPVs que são de alto risco na evolução das lesóes que desencadearão o câncer cervical. A infecção genital é comum em pessoas jovens do sexo feminino, normalmente é transitória. Algumas mulheres infectadas evoluem para o câncer cervical, podendo ser devido a fatores externos e/ou genéticos na oncogênese. A partir da genômica desenvolveram-se duas vacinas contra o HPV, que são aprovadas no Brasil: Cervarix da GlaxoSmithKline e Gardasil da Merck Sharp \& Dohme, contendo a proteína $L 1$ do capsídeo viral, produzidas através da tecnologia do DNA recombinante para a obtenção de partículas análogas às virais $(V L P S)$ de dois vírus mais comuns nos cânceres cervicais: $H P V 16$ e o HPV18, a quantidade de $V L P$ s, assim como o sistema adjuvante diferem em cada vacina [15].

\section{Carcinoma de mama}

$\mathrm{O} c D N A$ microarray é uma ferramenta genômica sub-classificada na proteoma, que visa identificar 
os padróes moleculares dos tumores e identificar novos e melhores marcadores clínicos, analisando os padrôes da expressão gênica em milhares de genes, tem como vantagem identificar a diversidade entre os tumores que possuem semelhança histopatológica. Outra ferramenta genômica dentro da proteoma é a técnica de tissue microarray (TMA), que serve para identificar os padróes moleculares da carcinogênese e novos e melhores marcadores clínicos. Por meio de estudos da proteoma conseguimos analisar a expressão global, revelando proteínas ou genes codificantes, envolvidos nas alteraçóes do estado fisiológico, comparando a concentração celular antes e após estas alteraçóes. A técnica do tissue microarray (TMA) determina perfis de expressão proteica em um grande número de amostras teciduais agrupadas, validando os achados do $c D N A$ microarray nos carcinomas de mama [9].

\section{Marcadores biológicos no câncer de boca}

A oncoproteina $p 53$ nada mais é que um marcador biológico no câncer de boca, sua identificação serve para diagnóstico e prognóstico do câncer, destacando a presença dessas proteínas em lesóes de boca ocasionadas pelo processo neoplásico. Possui 393 aminoácidos e um peso molecular de $53 \mathrm{kD}$ e tem como função realizar atividade regulatória durante o ciclo celular. É uma fosfoproteína nuclear codificada por um gene mapeado no braço curto do cromossomo 17 (na banda 17p13.1), o gene TP53 codifica um $R N A m$ de 2,8 kb. Merece destaque, pois atua na transcrição gênica, regulação do ciclo celular, duplicaçáo centrossômica, apoptose, reparo do DNA, diferenciação, desenvolvimento celular e senescência [11].

\section{Nutrição no pós-genoma}

No pós-genoma humano surge a nutrigenômica na nutrição, tendo como objeto de estudo a interação gene-nutriente, em busca de dietas personalizadas, com base no genótipo. Pois os nutrientes e compostos bioativos dos alimentos ( $C B A s)$ influenciam o funcionamento do genoma e podem causar variaçóes em seus genes e nas maneiras que os indivíduos respondem às dietas [5].

A nutrigenômica visa promover a saúde e diminuir os riscos de doenças como o câncer, conhecendo o resultado da combinação de milhóes de polimorfismos distribuídos no genoma, prevendo as interaçôes dessas diversidades genéticas com fatores externos como os alimentos, diminuindo os riscos de desenvolvimento das alteraçôes no genoma [3].

\section{Proteínas quinases}

As proteínas quinases são definidas como enzimas que catalisam a fosforilação de proteínas, através da transferência de um grupo fosforila de ATP e também em casos excepcionais de GTP para treonina, serina (quinase específica para Ser/Thr) ou resíduos de tirosina (quinase específica para Tyr), cuja fosforilação destes resíduos é desencadeada por estímulos extracelulares e intracelulares, fornecendo um mecanismo altamente eficiente para o controle de atividades das proteínas. Grande parte dos cânceres se relaciona com a desregulaçáo das proteínas quinases, normalmente ocorre por meio da mutação gênica, desencadeando uma superexpressão ou danificação de inibidores endógenos. As proteínas quinases destacam-se porque estão relacionadas com a diferenciação, proliferação celular e transdução de sinais, sendo alvos terapêuticos, servindo para esclarecimento do mecanismo molecular da açáo de muitos medicamentos e identificaçáo de novas moléculas com capacidade inibitória, o resultado é obtido através da cristalografia de raios- $X$ das diversas quinases nas conformaçóes ativas e inativas [13].

\section{Enfermagem na era genômica}

Com a evolução da ciência, o enfermeiro deve possuir conhecimento dos recursos da genômica aliado à bioinformática, visando o cuidar de maneira integral e individualizado. Deve realizar planos de cuidados e rotinas fundamentadas nas interpretaçóes dos resultados dos exames dos genes de cada paciente, utilizando sistemas computadorizados de informaçóes em saúde, como o prontuário eletrônico do paciente, que deve possuir recursos de integração com bases de dados moleculares, epidemiológicas e clínicas, para que possa analisar os dados do paciente com integração continua para obter uma resposta eficiente para tais tendências [9].

A genética e genômica surgiram como as principais ciências de atenção à saúde no século XXI, transformando as recomendaçóes para o ensino, prática, regulação e controle da qualidade da assistência de enfermagem. $\mathrm{O}$ uso das informaçóes genéticas e genômicas são cada vez mais importantes 
na prestação de cuidados em saúde e eficazes. Genética incide sobre os genes individuais do genoma em geral, abordando as condiçóes resultantes dos erros em um único gene. Estas alteraçôes genômicas são multifacetadas conhecidas por contribuírem para certo número de condiçóes mais frequentes dos pacientes, incluindo algumas das doenças crônicas, tendo muitas implicaçóes para a prática de enfermagem [16,17].

Historicamente, enfermeiros, envolvidos na genética clínica nos Estados Unidos, adotaram um modelo de abordagem médica para compreender e praticar genética. Com frequência eles minimizaram sua própria perspectiva de enfermagem, a fim de se encaixarem na função estabelecida e legitimada de conselheiro genético, o qual é treinado em genética médica e certificado em aconselhamento genético [18].

O teste genético é a análise do DNA humano, RNA, cromossomos, proteínas e certos metabólitos, a fim de detectar informaçóes hereditárias dos genótipos que desencadeiam doenças através de mutaçôes nos fenótipos ou cariótipos para fins clínicos. Os testes genéticos podem produzir informações específicas sobre os riscos futuros, caracterizar mais doenças, estabelecer o tratamento adequado ao perfil genético dos indivíduos e de suas doenças. Todos os enfermeiros devem ter preparação para a prestação de serviços em genética, devendo receber uma educação adequada, que inclua informaçóes básicas sobre a genética e os cuidados na saúde em genética, bem como o conhecimento das implicaçóes e complexidades dos testes genéticos, capacidade de interpretar os resultados e conhecimentos sobre os aspectos éticos, sociais, psicológicos e consequências dos testes genéticos [19].

$\mathrm{O}$ foco da enfermagem deve ser a identificação e priorização das estratégias para promover esclarecimento e apoio aos clientes que manifestam ou estão em risco de desenvolver uma doença genética, utilizando vários resultados de enfermagem para monitorar a eficácia do aconselhamento genético nas necessidades dos indivíduos, através de reunião psicossocial focada na relação dos aspectos genéticos e saúde [19].

Os enfermeiros podem promover o uso de tecnologias em pesquisa genômica e de informação no contexto da saúde, biologia e sociedade, bem como na pesquisa de enfermagem, prática, educação e política [20].

\section{Conclusão}

Após o mapeamento do genoma humano destacamos os benefícios, que são os novos acontecimentos na ciência como: Microarrays, MicroRNAs, Marcadores séricos e espectrometria de massa, maior precisão no diferenciamento do Papiloma vírus, marcadores de Carcinoma de mama, Marcadores biológicos no câncer de boca, Nutrição no pós-genoma, Proteínas quinases, Enfermagem na era genômica, revelando-nos como resultados grandes avanços na prevenção, diagnóstico e tratamento do câncer em pacientes adultos.

Os estudos genômicos têm como objetivo determinar todas as funçóes de todos os genes e saber das suas interaçóes com fatores ambientais, servindo como ferramentas metodológicas e científicas para o avanço na compreensáo dos mecanismos envolvidos no câncer.

A maior parte dos cânceres está associada com a desregulação de proteínas, geralmente através da mutação gênica, que conduz a uma superexpressão ou danificação dos inibidores endógenos. Outras doenças sérias como diabetes e doenças cardiovasculares também estão associadas com esse desequilíbrio, mas os estudos dos fenômenos moleculares para a carcinogênese e os fatores que levam a sua malignidade têm servido para avanços no diagnóstico e prognóstico, em função da diferenciação, proliferação celular e transdução de sinais, sendo importantes para alcançarem os métodos terapêuticos mais adequados para controle e cura do câncer.

Desta maneira, podemos analisar que a partir da conclusão do mapeamento do genoma humano a ciência entrou em uma nova etapa da sua evolução que nos traz muitos benefícios, desde a promoção da saúde, diagnóstico e tratamento, através de alimentos, exames e fármacos, cada vez mais especializados e precisos em prol da saúde proporcionando longevidade e bem estar dos seres humanos. No entanto, ainda enfrentamos o preconceito da populaçáo com alimentos/medicamentos modificados geneticamente, necessitando esclarecimento a populaçáo sobre essa nova etapa de evolução do campo cientifico. 


\section{Referências}

1. Santos MF, Nascimento LC. Perspectivas históricas do projeto genoma e a evolução da enfermagem. Rev Bras Enfermagem 2006;59(3):358-61.

2. Guindalini Ca, Tufik S. Uso de microarrays na busca de perfis de expressão gênica - aplicação no estudo de fenótipos complexos. Rev Bras Psiquiatr 2007;2(4):370-74.

3. Conti A, Moreno FS, Thomas P. Nutrigenônica: revolução genômica na nutrição. Ciênc Cult 2010;62(2):4-5.

4. Marin HF, Cunha ICKO. Perspectivas atuais da informática em Enfermagem. Rev Bras Enferm 2006;59(3):354-7.

5. Fialho E, Moreno FS, Ong TP. Nutrição no pós-genoma: fundamentos e aplicaçóes de ferramentas ômicas. Rev Nutr 2008;21(6):757-66.

6. Payão SLM, Segato R, Santos RR. Controle genético das células-tronco humanas cultivadas. Rev Bras Hematol Hemoter 2009;31(1):12-22.

7. Castie LD, Guilam MCR, Silva PRV, Valero JS. Os riscos genômicos e a responsabilidade pessoal em saúde. Rev Panam Salud Publica 2006;19(3):189-97.

8. Salvato F, Carvalho MCG. Métodos e estratégias em proteômica e suas aplicaçóes na área vegetal Métodos e estratégias em proteômica e suas aplicações na área vegetal. Ciência Rural Santa Maria 2010;40(3):727-34.

9. Vieira DSC, Dufloth RM, Schmitt FCL, Zeferino LC. Carcinoma de mama: novos conceitos na classificação. Rev Bras Ginecol Obstet 2008;30(1):42-7.

10. Pellizzon RF, Montero EFS, Población DA, Monteiro $\mathrm{Ra}$, Castro RCF. Revistas brasileiras publicadoras de artigos científicos em cirurgia. III: análise das instruçóes aos autores baseada na estrutura dos requisitos de Vancouver. Acta Cir Bras 2007;22(6):503-10.

11. Moura SAB, Catão MH, Gerbi M, Beltrão RV, Sales MAO, Costa LJ. Marcadores biológicos no câncer de boca. IJD. International Journal of Dentistry 2006;5(2):58-62.

12. Ricarte Filho JCM, Kimura ET. MicroRNAs: nova classe de reguladores gênicos envolvidos na função endócrina e câncer. São Paulo. Arq Bras Endocrinol Metab 2006;50(6):1102-7.

13. Silva BV, Horta BAC, Alencastro RB, Pinto AC. Proteínas quinases: características estruturais e inibidores químicos. Quím Nova 2009;32(2):453-62.

14. Carvalho PC, Fischer JSG, Degrave WM, Carvalho MGC. Marcadores séricos e espectrometria de massa no diagnóstico do câncer. J Bras Patol Med Lab 2006;42(6):431-36.

15. Rosa MI, Medeiros LR, Rosa DD, Bozzeti MC, Silva FR, Silva BR. Papilomavírus humano e neoplasia cervical. Cad Saúde Pública 2009;25(5):953-64.

16. Jean Jenkins, Kathleen A. Calzone. Establishing the essential nursing competencies for genetics and genomics. The Online Journal of Issues in Nursing 2007;39(1):101-22.

17. Badzek L, Martha JD, Turner, Jean F, Jenkins RN. Genomics and nursing practice: advancing the nursing profession. The Online Journal of Issues in Nursing. 2008;13(1).

18. Anderson GW, Monsen RB, Rorty MV. Enfermagem e genética: uma crítica feminista rumo ao trabalho em equipes transdisciplinares. Rev Estud Fem 2006;14(2):423-43.

19. Santos MF, Ramos ES. Genomic-based nursing care for women with Turner Syndrome: genomic-based nursing care. Rev Latinoam Enfermagem 2006;14(5):645-50.

20. Feetham $S$, Thomson E. Nursing Leadership in Genomics for Health and Society. Journal of Nursing Scholarship 2005;37(1):95-192. 